\title{
The influence of solar radiation on the distribution of temperatures in historic masonry
}

\author{
P. Beran \\ Institute of Theoretical and Applied Mechanics, \\ v.v.i. AS CR, Czech Republic
}

\begin{abstract}
One of the degradation processes in historic masonry is caused by cyclic thermal stress. Thus this paper is focused on the definition of the loading of historical objects. The component of this research was to detect the relations of wall maximal surface temperatures to its orientation to the cardinal points, material characteristics and speed of the wind around the surface. These relations were obtained by means of the 1-D numerical model of the wall. One surface of the wall was exposed to solar radiation and outside air, the other surface was exposed only to outside air. The simulations of the temperature response of the wall on climatic actions during July 2006 were used to define maximal surface temperatures. The maximal surface temperature of the wall significantly depends on its orientation to the cardinal points, declination of the surface from vertical, the speed of wind around the surface, coefficient of absorption of solar radiation, heat conduction of the wall and volume heat capacity. These results help to detect the facades of historic objects and historic materials which are highly stressed by temperature actions. The amount of money for renovation is limited, so this information could be used during planning of the renovation of the historical building. For example, if the failures on historic facades are caused by temperature stresses, the reduction of solar absorption coefficient by cleaning the dirty surfaces could be used only on the extremely loaded facades. Also the accurate selection of the repair material with respect to thermal expansion compatibility can reduce thermal stress.

Keywords: temperature, solar radiation, material properties, numerical model, material compatibility, cultural heritage.
\end{abstract}




\section{Introduction}

The historical buildings are usually created from ancient masonry. Durability of these historical buildings is based on durability of masonry that degrades by several reasons. One of the degradation processes is caused by the thermal cyclic strain. The magnitude of the stress depends on the distribution of the temperatures in the masonry. The norm "Eurocode 1-part 1-5: General actions - Thermal actions" defined thermal actions on buildings. But only the brief information values of the surface temperatures of the exterior building wall are specified in this norm. Therefore this paper is focused on the deep analysis of the character and values of temperatures in the historic masonry.

In study (Drdácký and Beran [6]) is described model of historic masonry which is focused on thermal stress caused by different thermal expansion of mortar and stone. The maximal values of stress were detected on the insolated surface i.e. where is the maximal temperature difference. This temperature difference depends on the actual temperature of masonry and the reference temperature. The reference temperature is for example the temperature when the masonry was built up. The values of reference temperature wary and depends on actual weather conditions during construction. Typical values in the Czech Republic are between $5-25^{\circ} \mathrm{C}$. The maximal temperature difference can be caused by extreme cooling or heating during real climatic conditions. During extreme cooling the minimal surface temperature of the wall is usually approximately equal the air temperature, which is approximately $-20^{\circ} \mathrm{C}$ in Prague [6]. During the extreme heating is the maximal surface temperature affected by insolation and air temperature. From the previous information is obvious that maximal temperature difference between actual and reference temperature is achieved when the surface temperature is maximal. Therefore the aim of this paper was to detect the relations of the maximal temperature in the wall to the orientation of the surface to the cardinal points, the coefficient of the heat transfer, coefficient of the heat conduction and volume heat capacity.

The analysis of the temperatures is realized by means of numerical modeling of the temperature response of the exterior wall to the climatic actions. The modeled climatic actions are the air temperature in the exterior of the building, the solar radiation, the impact of the flow. Aim of this paper is to detect maximal surface temperatures of the insolated surface during summer in Prague, Czech Republic. The relation of maximal surface temperature to the orientation of the wall to the cardinal points and its relation to absorbability of the surface are described in the paper. Also the impact of the material characteristic of the wall and the speed of the flow around the surface are included in the paper.

\section{Description of the numerical model}

\subsection{Numerical model of the wall}

The length and high of the wall is usually significantly higher than its thickness, thus the heat transfer in the wall runs dominantly in the direction of normal of 
the surface. Therefore the complex 3-D heat transfer in the wall (1) can be replaced by the 1-D heat transfer. See equation (2).

This study is based on one dimensional finite element model of masonry section. The numerical model represents the cross-section of the wall of $0.45 \mathrm{~m}$ thickness. One side of the wall was exposed to solar radiation and outdoor air, while the opposite side was exposed only to the outdoor air. The transient heat transfer in 3-D, according to [1], is described by equation (1).

$$
\begin{aligned}
\lambda \nabla^{2} T & =\rho c \frac{\partial T}{\partial t} \\
\lambda \frac{\partial^{2} T}{d x^{2}} & =\rho c \frac{\partial T}{\partial t}
\end{aligned}
$$

c specific heat capacity, $\mathrm{J} /(\mathrm{kg} \mathrm{K})$

$T$ temperature, ${ }^{\circ} \mathrm{C}, \mathrm{K}$

$x \quad$ coordinate, distance from the insolated surface, $\mathrm{m}$

$\lambda \quad$ coefficient of heat conduction, $\mathrm{W} /(\mathrm{m} \mathrm{K})$

$\rho \quad$ bulk density, $\mathrm{kg} / \mathrm{m}^{3}$

The finite element method was used for the numerical solution of equation (2). Alternatively, an analytical solution can be used which is described in Carslaw and Jaeger [7]. Also the boundary conditions which represent the values of heat flux on the surfaces of the wall were added into the model. The impact of the air temperature and flow was simulated by equation (3).

$$
q=h\left(T_{a}-T_{s}\right)
$$

$h \quad$ heat transfer coefficient, $\mathrm{W} /\left(\mathrm{m}^{2} \mathrm{~K}\right)$

$q$ density of the heat flux, $\mathrm{W} / \mathrm{m}^{2}$

$T_{a} \quad$ air temperature around the surface; the temperatures measured on the meteorological station Prague Karlov were used as the air temperatures around the surface, ${ }^{\circ} \mathrm{C}, \mathrm{K}$

$T_{s} \quad$ surface temperature, ${ }^{\circ} \mathrm{C}, \mathrm{K}$

Only the intensity of global solar radiation which falls on the horizontal surface is measured in Prague. This was the reason to create simplified model how to compute the intensity of global solar radiation which falls on the arbitrarily oriented surface of the wall. The idea was that whole solar radiation is the direct radiation. The scheme how was computed is shown in figure 1 . The mathematical formulation is described by equations (4)-(6).

$$
\mathbf{I}_{\mathrm{o}}=\frac{\mathbf{I}_{\mathbf{h}}}{\sin \gamma}
$$

$\mathbf{I}_{\mathbf{h}} \quad$ intensity of solar radiation incident on a horizontal surface, the values measured at the Prague-Karlov meteorological station was used, $\mathrm{W} / \mathrm{m}^{2}$

$\mathbf{I}_{\mathbf{0}}$ intensity of solar radiation incident on a surface perpendicular to the direction of the solar radiation, $\mathrm{W} / \mathrm{m}^{2}$

$\gamma \quad$ solar altitude, ${ }^{\circ}$ 
Vertical section

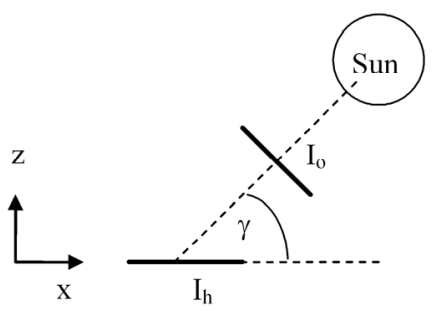

3-D scheme

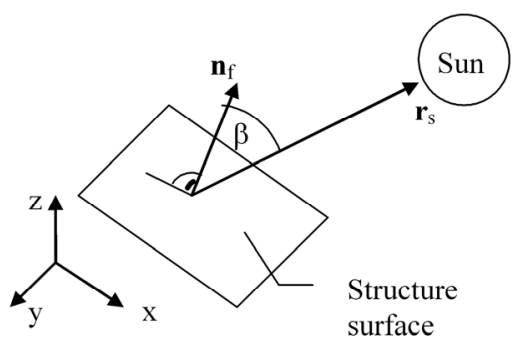

Figure 1: Scheme how was computed the intensity of global solar radiation which falls on arbitrarily oriented surface.

$$
\cos \beta=\mathbf{n}_{f} \mathbf{r}_{s}
$$

$\mathbf{n}_{\mathbf{f}} \quad$ base vector of the normal of the appropriate surface

$\mathbf{r}_{\mathrm{s}} \quad$ base vector of the position of the Sun in the sky, function of time

$\cos \beta$ the value of the scalar product between the vector of the surface normal and the vector of the position of the Sun in the sky, function of time

$$
\mathbf{q}_{\mathbf{a}}=\alpha \mathbf{I}_{\mathbf{0}} \cos \beta
$$

qa density of the heat flux which is absorbed by the structure surface, $\mathrm{W} / \mathrm{m}^{2}$

$\alpha \quad$ coefficient of the absorption of the solar radiation - the values can be $(0 ; 1),-$

This model of formulation of boundary conditions was successfully verified in previous study Beran et al. [2].

\subsection{Method of the analysis of the temperature fields in the wall}

By the numerical model which is described in previous chapter was simulated the period of the whole month (July 2006). The July 2006 was the one of the hottest moth in Prague during the history of the measurements of temperature on meteorological stations.

The transient simulation of the heat transfer was used. The heat inertial of the wall of thickness $0.45 \mathrm{~m}$ is approximately three days. The maximal value of temperatures in the wall was detected in the second half of the simulated month; so the heat inertial of the wall did not affect the value of maximal temperature in it. The initial temperature of the wall in model was $20^{\circ} \mathrm{C}$ which is approximately the average air temperature during July in Prague. 
The temperatures in the wall were computed by the numerical model during July 2006. The maximal value of these temperatures was found for the particular material characteristics, orientation of the surface to the cardinal points and coefficient of heat transfer. The computation of temperatures in the wall was made again for little different analyzed properties. Only one analyzed property was different, the others were the same. The aim of this was to detect relation of the maximal surface temperature to the analyzed property.

The boundary conditions are shown in figure 2. It is obvious that the boundary conditions are random values which can not be easily approximated by the simple mathematical function. This is the reason why numerical solution of the heat transfer equation (2) was used. In figure 3 is plotted the history of the temperature of the insolated surface during the time when the maximal surface temperature was detected.

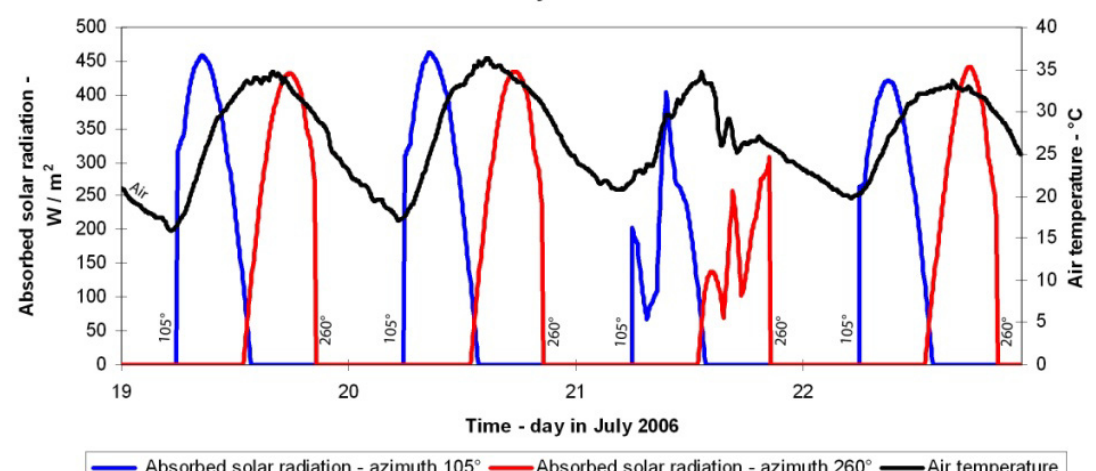

Figure 2: Boundary conditions of the part of the analysed period - vertical wall.

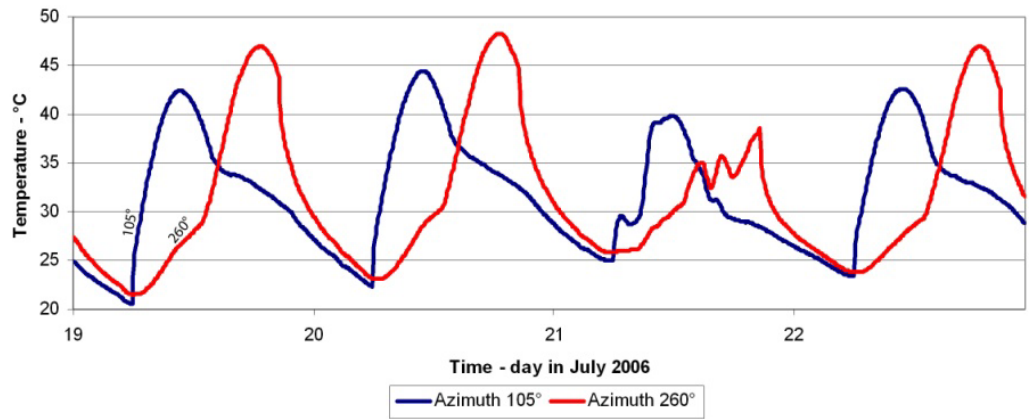

Figure 3: $\quad$ History of the temperatures - numerical model - July 2006; Used material characteristics and parameters: coefficient of heat conduction $1.4 \mathrm{~W} /(\mathrm{m} \mathrm{K})$, specific heat capacity $840 \mathrm{~J} /(\mathrm{kg} \mathrm{K})$. bulk density $2400 \mathrm{~kg} / \mathrm{m}^{3}$, coefficient of heat transfer $15 \mathrm{~W} /\left(\mathrm{K} \mathrm{m}^{2}\right)$, absorbability of solar radiation $60 \%$, vertical wall. 


\subsection{Material characteristics and other properties}

Aim of this study is to show dependence of maximal surface temperature on the material characteristics of the wall and parameters of the ambient space.

\subsubsection{Typical material characteristics and other parameters}

The sandstone is the typical material used in Prague for the historical buildings. Therefore the material characteristics of one kind of sandstone were used as the basis. One of the parameters used in analysis is the heat transfer coefficient. Its value significantly depends on the speed of wind $[1,3]$. The value defined by the norm [3] was used as the reference one for summer.

$$
\begin{aligned}
& \mathrm{c}=840 \mathrm{~J} /(\mathrm{kg} \mathrm{K}) \\
& \mathrm{D}=0^{\circ} \\
& \mathrm{h}=15 \mathrm{~W} /\left(\mathrm{m}^{2} \mathrm{~K}\right) \\
& \alpha=0.6=60 \% \\
& \lambda=1.4 \mathrm{~W} /\left(\mathrm{m} \mathrm{K}^{3}\right) \\
& \rho=2400 \mathrm{~kg} / \mathrm{m}^{3}
\end{aligned}
$$

specific heat capacity
declination; this value is valid for vertical wall
heat transfer coefficient
coefficient of absorption of the solar radiation
coefficient of heat conduction
bulk density

\subsubsection{Material characteristics and other parameters used in analysis}

The simulation was made for all relevant material characteristics of the historic masonry and other parameters.

$$
\begin{aligned}
& \mathrm{A}=0-360^{\circ} \\
& \mathrm{C}=1.1-2.9 \mathrm{MJ} /\left(\mathrm{m}^{3} \mathrm{~K}\right) \\
& \mathrm{D}=-90-+90^{\circ} \\
& \mathrm{h}=8-40 \mathrm{~W} /\left(\mathrm{m}^{2} \mathrm{~K}\right) \\
& \alpha=0.4-0.8 \\
& \lambda=0.45-4.0 \mathrm{~W} /(\mathrm{m} \mathrm{K})
\end{aligned}
$$

azimuth

volume heat capacity surface (wall) declination heat transfer coefficient coefficient of absorption of the solar radiation coefficient of heat conduction
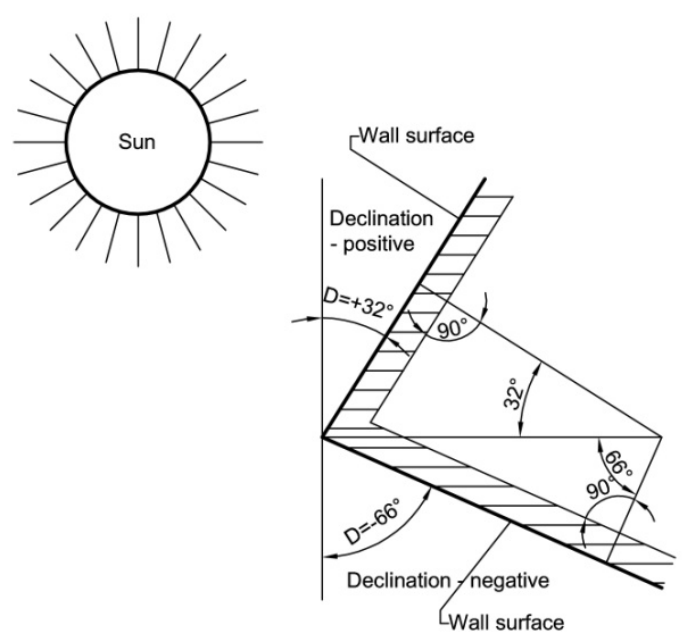

Figure 4: Definition of declination. 


\section{Results}

\subsection{Orientation to the cardinal points}

The relation of maximal surface temperature to its orientation to the cardinal points is plotted in figures 5 and 6 . The azimuth of the normal of the vertical surface or projection of the surface normal to the horizontal plane is on the horizontal axis in figures 5 and 6 . The maximal surface temperature during July 2006 is on the vertical axis in figures 5 and 6 . These figures are valid for Prague which downtown has latitude of $50^{\circ} 5^{\prime}$ north.

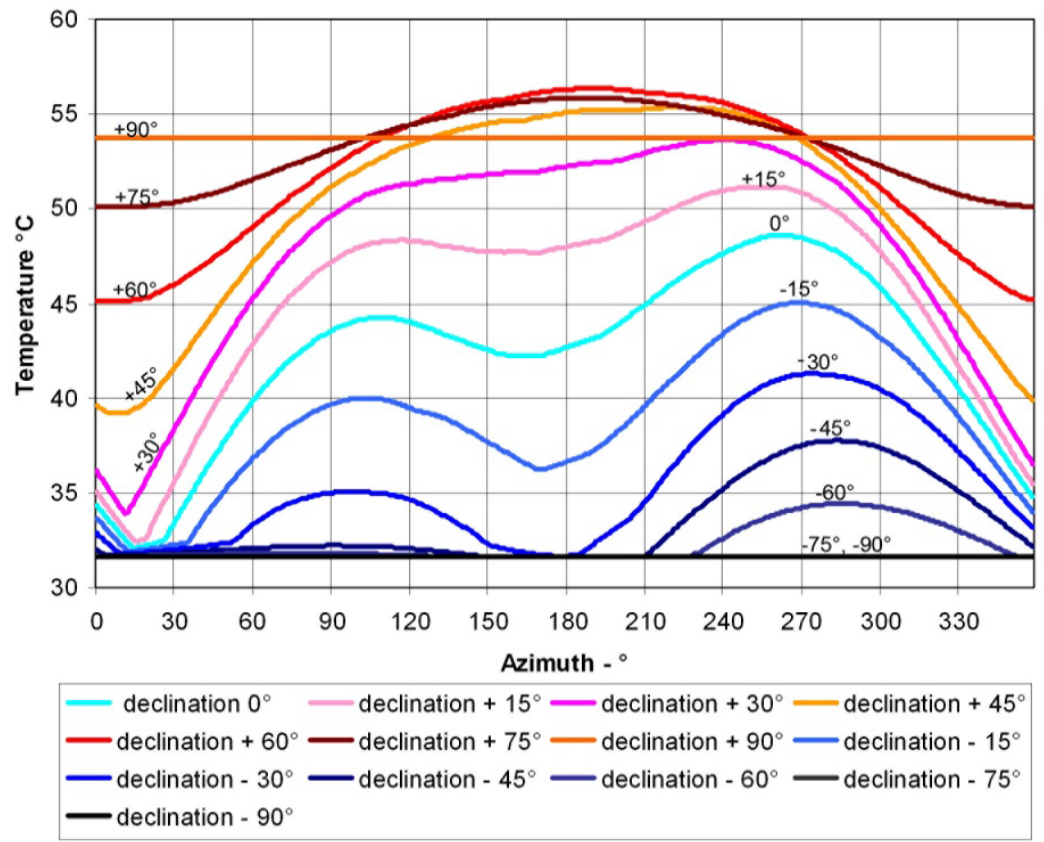

Figure 5: Dependence of maximal surface temperature on its orientation to the cardinal points - July 2006; the typical material characteristics and parameters were used.

The results show that the maximal surface temperature significantly depends on its orientation to the cardinal points. The maximal value of the surface temperature of eastern surface is reached in the morning, when the air is cold and solar radiation irradiates by maximal intensity. The maximal value of the western surface temperature is achieved in the afternoon when air is hot and solar radiation irradiates this surface by maximal intensity. This is the reason why the lines in figures 5 and 6 are not symmetric. See figures 2 and 3 . 


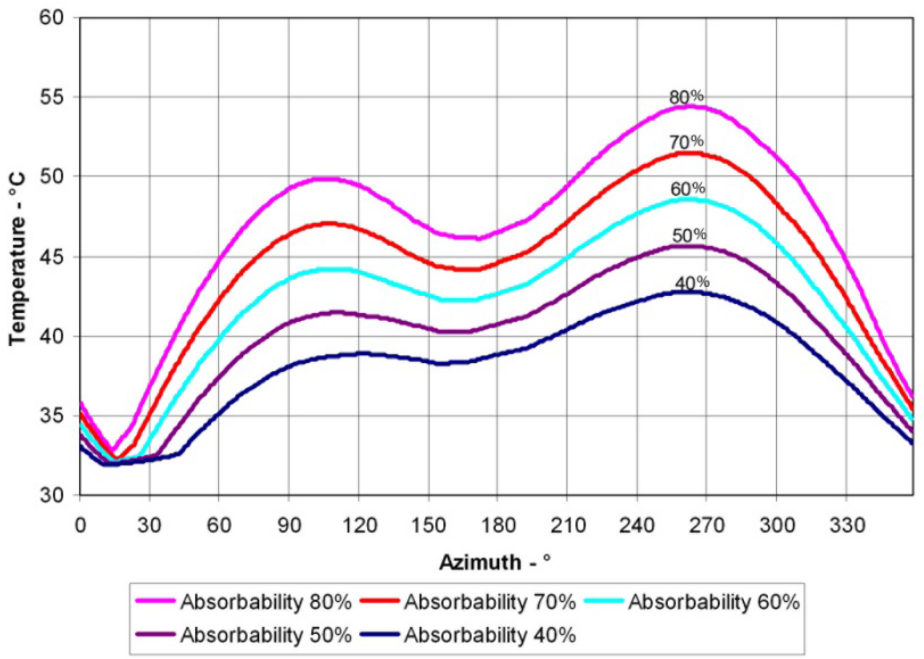

Figure 6: Dependence of maximal temperature of the vertical wall (surface) on its orientation to the cardinal points - July 2006; the typical material characteristics and parameters were used.

The norm [4] Eurocode 1 defined the maximal surface temperature during summer by the equation (7).

$$
T_{\text {out }}=T_{\max }+T_{i=3,4,5}
$$

$T_{\text {out }} \quad$ maximal temperature of the exterior surface, ${ }^{\circ} \mathrm{C}$

$T_{\max } \quad$ maximal air temperature in shadow, ${ }^{\circ} \mathrm{C}$

$T_{i=3,4,5}$ rice of temperature due to solar radiation with respect to coefficient of absorption of solar radiation and orientation of surface to the cardinal points, ${ }^{\circ} \mathrm{C}$

The maximal surface temperature of the un-insolated surface of the wall with typical material characteristic and thickness $0.45 \mathrm{~m}$ was $32.2^{\circ} \mathrm{C}$. The maximal air temperature during July 2006 was $36.3^{\circ} \mathrm{C}$. The difference between maximal surface temperature and air temperature is $-3.9^{\circ} \mathrm{C}$. This difference is caused by the high heat inertial of the massive (compact) wall of the historical building, the history of the air temperature in the exterior and heat transfer coefficient. The uninsolated surface of the historical building wall has lower temperature than the value which is defined by norm [4]. With respect to values defined by the equation (7), the norm [4] defined safe value of the maximal temperature of the un-insolated surface. It is necessary to note that norm [4] defined only the information values of temperatures.

However, the norm [4] defines for eastern vertical surface with absorption 0.5 $(50 \%)$ the value " $\mathrm{T}_{3}=0^{\circ} \mathrm{C}$. With respect that maximal air temperature during analyzed period was $36.3^{\circ} \mathrm{C}$. The eastern vertical surface should have maximal 
temperature $36.3^{\circ} \mathrm{C}$, but simulation showed that this value is $40.8^{\circ} \mathrm{C}$. For absorption $0.7(70 \%)$ is the value " $\mathrm{T}_{4}=+2{ }^{\circ} \mathrm{C}$ " so the maximal value for eastern vertical surface is $38.3^{\circ} \mathrm{C}$ but simulation showed that this value is $46.4^{\circ} \mathrm{C}$. The norm [4] for eastern surface defined unsafe values of temperature loading.

For the surfaces oriented to the south, south-west, west and horizontal is the maximal surface temperature defined by [4] $60.3^{\circ} \mathrm{C}$ when the absorption of solar radiation is $60 \%$. The maximal value of the temperature obtained through the simulation is for south $42.7^{\circ} \mathrm{C}$ in July but during August can be about $5^{\circ} \mathrm{C}$ higher. The maximal value of the temperature obtained through the simulation is for the south-west $46.5^{\circ} \mathrm{C}$ respectively for the west $48.5^{\circ} \mathrm{C}$. The maximum for the surface which is not vertical is $56.4^{\circ} \mathrm{C}$. Thus the norm [4] in this case defines safe values of temperature action for the typical material characteristics of the walls of historical buildings and other typical parameters used in analysis.

The results plotted in figure 5 show that maximal surface temperature significantly depends on the declination of the surface from vertical. These results can be used for the selection of parts (facades) of the historical building where the temperature action is high and thermal stress can cause damage of the historical buildings or their parts.

\subsection{The impact of wind - coefficient of heat transfer}

The results showed in fig. 7 were computed by the numerical model. The fix value of heat transfer coefficient was used through the simulations of the temperature response of the wall to the climatic actions during July 2006.

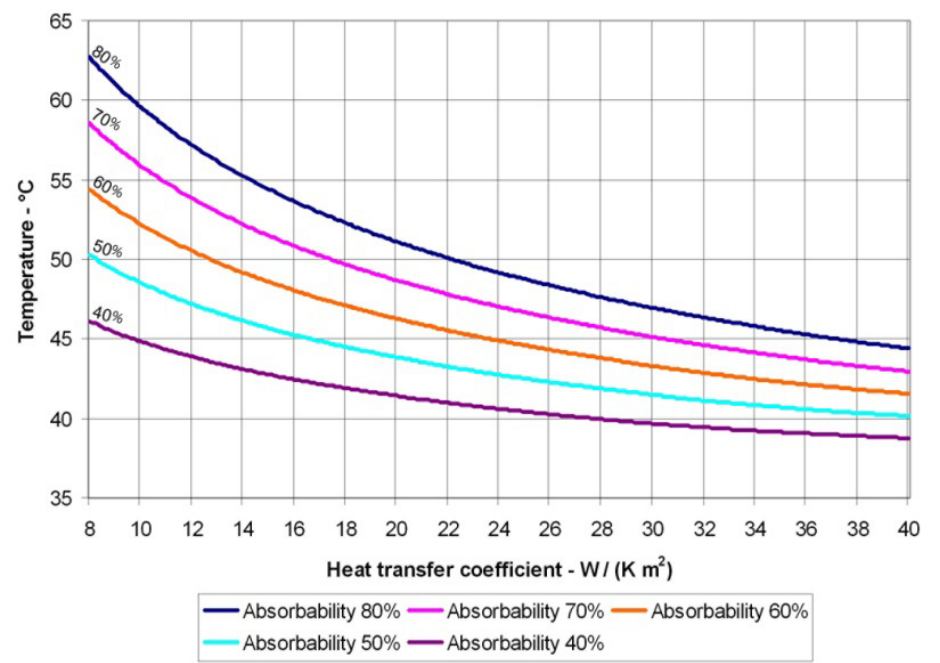

Figure 7: Dependence of maximal surface temperature of the vertical insolated wall (surface) on the heat transfer coefficient - July 2006; the typical material characteristics and parameters were used, Azimuth $=262^{\circ}$. 
The temperature response of the wall significantly depends on the heat transfer coefficient. The value of the coefficient of heat transfer in exterior is composed by the heat transfer coefficient which is caused by convection and by the heat transfer coefficient which is caused by radiation; approximate value is $5 \mathrm{~W} /\left(\mathrm{m}^{2} \mathrm{~K}\right)$. Heat transfer coefficient is approximately defined by the equation (8) [3].

$$
h_{c e}=4+4 v
$$

$h_{c e} \quad$ heat transfer coefficient which is caused by convection, $\mathrm{W} /\left(\mathrm{m}^{2} \mathrm{~K}\right)$

$v \quad$ speed of wind around the surface, $\mathrm{m} / \mathrm{s}$

The range used values of the heat transfer coefficient corresponds with the speed of wind in interval $(0 ; 8) \mathrm{m} / \mathrm{s}$. Thus the realistic values of heat transfer coefficient were used.

\subsection{The influence of material characteristics of the wall}

The temperature response of the wall on the thermal action depends significantly on its material characteristics. The impact of combination of the particular material characteristics can increase or decrease the maximal values of temperatures. See in figures 8-10.

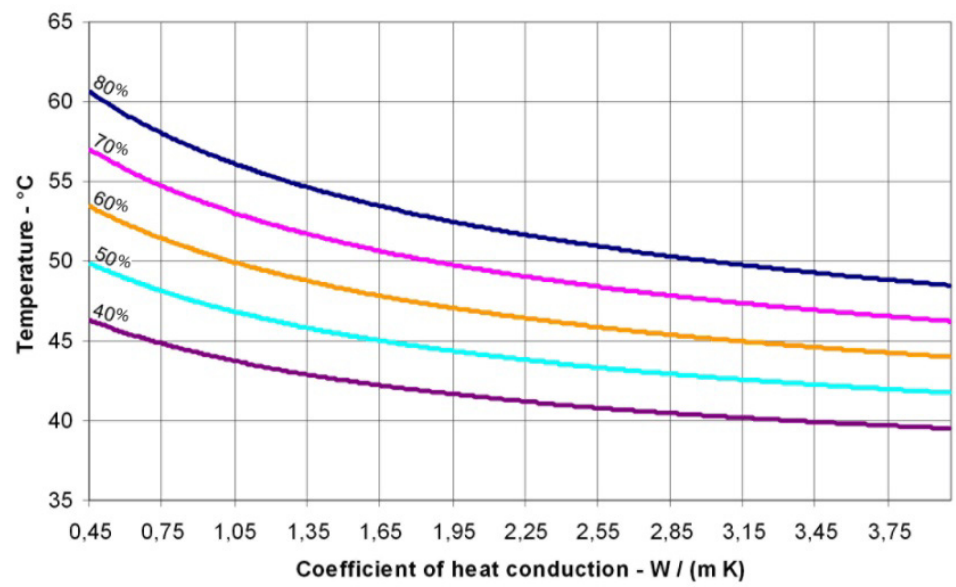

- Absorbability $80 \%$ - Absorbability $70 \%$ - Absorbability $60 \%$
Absorbability $50 \%$ - Absorbability $40 \%$

Figure 8: Dependence of maximal surface temperature of the vertical insolated wall (surface) on the coefficient of heat conduction - July 2006; the typical material characteristics and parameters were used, Azimuth $=262^{\circ}$. 


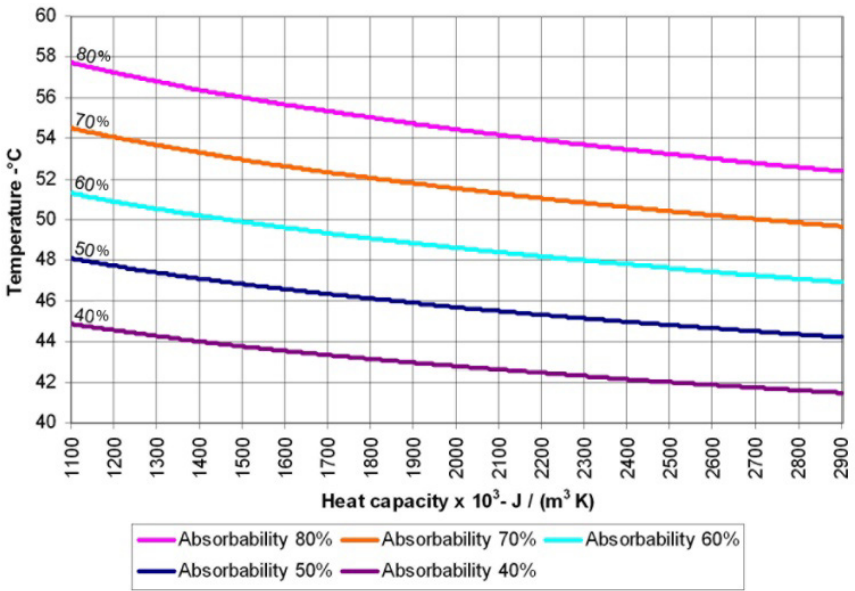

Figure 9: Dependence of maximal surface temperature of the vertical insolated wall (surface) on the volume heat capacity - July 2006; the typical material characteristics and parameters were used, Azimuth $=262^{\circ}$.

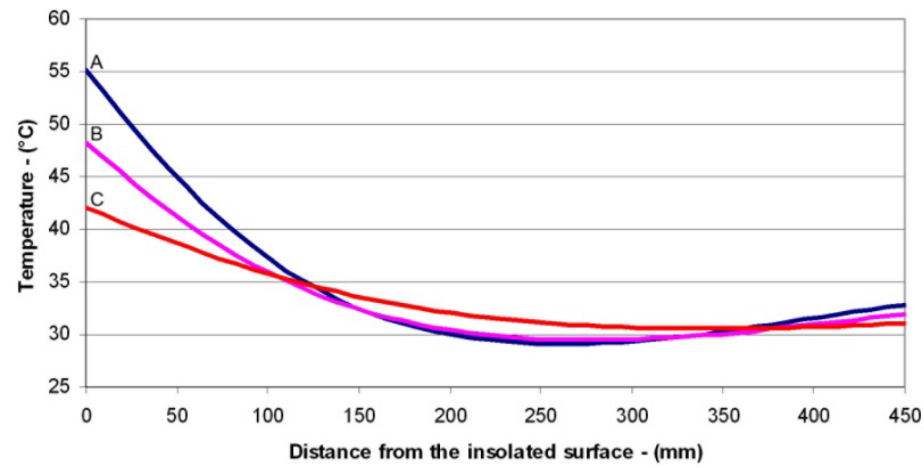

A - heat conduction $0,5 \mathrm{~W} /(\mathrm{m} \mathrm{K})$; volume heat capacity $1100 \mathrm{~kJ} /\left(\mathrm{m}^{3} \mathrm{~K}\right)$

B heat conduction $\mathrm{W} /(\mathrm{m} \mathrm{K})$; volume heat capacity $2000 \mathrm{~kJ} /\left(\mathrm{m}^{3} \mathrm{~K}\right)$

C - heat conduction $4 \mathrm{~W} /(\mathrm{m} \mathrm{K})$; volume heat capacity $2900 \mathrm{~kJ} /\left(\mathrm{m}^{3} \mathrm{~K}\right)$

Figure 10: Distribution of temperatures in the wall 0.45 in thickness; Dependence of temperatures in the wall on the combination of material characteristics - July 2006; the typical material characteristics and parameters were used, Azimuth $=262^{\circ}$.

\section{Conclusion}

The temperature response of the wall which is exposed to the solar radiation significantly depends on the orientation of its surface to the cardinal points, material characteristics and the speed of the wind around the surface. 
The relations of maximal surface temperature to the particular properties are mentioned above. These results could be used to determinate the historical buildings facades where the high temperatures cause the thermal stresses. Thermal stress can be during building renovation decreased by cleaning the surface. This could change the value of the absorption of solar radiation coefficient. The dependence of maximal surface temperature on heat conduction and heat capacity could alert to the materials which incline to higher temperature, consequently to higher thermal stress. These values of maximal surface temperatures will be used in the next research for the computation of thermal stress which is one of the criterions for selection of suitable repair material for historic masonry. This stress in historic masonry is caused by different thermal expansion of the mortar and stones, thus the accurate design of repair mortar with respect to the thermal expansion compatibility could reduce thermal stress.

The relations of maximal surface temperature in the masonry to the particular properties mentioned in this paper could be useful for design engineers in the region of central Europe and other countries with similar climatic conditions and north latitude. The valid norm [4] contains only information values of maximal surface temperatures during the summer and does not mention the relation of maximal surface temperature of the wall to its heat conduction and heat capacity.

\section{Acknowledgement}

This paper is based on results and experience acquired with support from Ministry of culture Czech Republic grant "Conditions and requirements of compatible care of the historical inorganic porous materials DF12P01OVV018".

\section{References}

[1] Sarit K Das, Process Heat Transfer - Alpha Science International Ltd., Harrow, UK, 2005.

[2] Beran P., Máca J., Fajman P., Temperature Effects on one Bay of St. Vitus` Cathedral, Acta Geodynamica et Geomaterialia., vol. 7, no. 2, pp. 209-217, 2010.

[3] ČSN EN ISO 6946 - Building components and building elements - Thermal resistance and thermal transmittance - Calculation method.

[4] ČSN EN 1991-1-5 - Eurocode 1: Actions on structures - Part 1-5: General actions - Thermal actions.

[5] Hens H., Building Physics, Heat, Air and Moisture - Ernst and Sohn Verlag für Architektur und technische Wissenschaften $\mathrm{GmbH}$ und Co. KG, Berlin, 2007.

[6] Drdácký M., Beran P. Compatible dilation limits of masonry joint mortars, International journal of architectural heritage, 2010, vol. 4, no. 2, p. 155-176,

[7] Carslaw H. S., Jaeger J. C., Conduction of heat in solids, Oxford, 1948. 